\title{
Microbial diversity in the larval gut of field and laboratory populations of the sugarcane weevil Sphenophorus levis (Coleoptera, Curculionidae)
}

\author{
R. Rinke ${ }^{1}$, A.S. Costa ${ }^{1}$, F.P.P. Fonseca ${ }^{1}$, L.C. Almeida ${ }^{2}$, \\ I. Delalibera Júnior ${ }^{3}$ and F. Henrique-Silva ${ }^{1}$ \\ ${ }^{1}$ Departamento de Genética e Evolução, \\ Universidade Federal de São Carlos, São Carlos, SP, Brasil \\ ${ }^{2}$ Centro de Tecnologia Canavieira, Piracicaba, SP, Brasil \\ ${ }^{3}$ Departamento de Entomologia e Acarologia, \\ Escola Superior de Agricultura "Luiz de Queiroz", \\ Universidade de São Paulo, Piracicaba, SP, Brasil \\ Corresponding author: F. Henrique-Silva \\ E-mail: dfhs@ufscar.br
}

Genet. Mol. Res. 10 (4): 2679-2691 (2011)

Received January 28, 2011

Accepted March 10, 2011

Published November 1, 2011

DOI http://dx.doi.org/10.4238/2011.November.1.1

\begin{abstract}
The sugarcane weevil, Sphenophorus levis, is a widespread sugarcane pest in Brazil. Sphenophorus levis may depend on microorganisms that inhabit its intestinal tract. We examined the diversity of the gut microbiota of S. levis, which was characterized using culturedependent and culture-independent methods. Analysis of 16S rRNA amplified directly from the gut community revealed the presence of 14 genera, one group from the Candidatus category, one uncultured group assigned to the family Flavobacteriaceae, and one uncultured group assigned to the family Enterobacteriaceae; all of them are members of the Alpha-Proteobacteria, Beta-Proteobacteria, Gamma-Proteobacteria, Firmicutes, and Bacteroidetes phyla. Microorganisms isolated through culture-dependent methods were classified according to morphological
\end{abstract}


parameters and by 16S rRNA gene sequences. In addition to bacteria, four filamentous fungi were isolated. A higher bacterial diversity was observed in field populations of larvae than in laboratory populations, according to the Shannon index (Field $\mathrm{H}^{\prime}=3.36$; Laboratory $\mathrm{H}^{\prime}=3.26$ ). Five genera of bacteria and two filamentous fungi were found to have cellulolytic activity. This is the first report of $S$. levis gut microbiota; it may contribute to development of strategies for controlling this sugarcane pest.

Key words: Sphenophorus levis; Microbiota; Sugarcane weevil; Cellulose-degrading activity

\section{INTRODUCTION}

Sugarcane (Saccharum spp) is one of the most important crops cultivated in Brazil; it is the main natural resource used in the production of ethanol, sugar and electricity. The importance of ethanol in particular is increasing as a potential source of clean energy. Ethanol is a potential alternative, particularly when produced in a sustainable way as is envisioned for sugarcane in Brazil (Sparovek et al., 2007). However, the sugarcane crop is attacked by insects that are responsible for a decrease in productivity. Among these insects, the sugarcane weevil Sphenophorus levis (Coleoptera: Curculionidae) has been causing losses to sugarcane farmers (Vanin, 1990). In the larval stage, the insect attacks the rhizome and destroys the plant tissue. The larvae block the basal part of the plant and rhizomes, leading to plant death. Several strategies have been applied to control the incidence and proliferation of S. levis, but without success, because larvae remain inside the plant, which makes it more difficult to combat the insects with most control strategies. For this reason, strategies for controlling S. levis are desirable.

There has been growing interest in developing novel approaches to control insect pests through gut microbiota study. An interesting study was performed with Dermolepida albohirtum larvae, where a subset of the bacterial community from Australian scarab pest, naturally associates with the scarab hindgut, was characterized and potential candidates for genetic manipulation strategies targeting the feeding activity of these beetles were identified (Pittman et al., 2008). Insect guts appear to be a reservoir for a large variety of as yet uncharacterized microbes and can play important roles in insect host physiology and nutrition. Symbiosis usually involves benefits for both the host insect and the microbes. The insect gut offers an environment where microbes can develop under good conditions with plentiful food resources (Santo Domingo et al., 1998a). On the other hand, endosymbionts are able to secrete enzymes responsible for the degradation of compounds found in the insect diet, helping in the digestion process and decreasing the toxicity of plant defense compounds (Dillon and Dillon, 2004).

Most of the microorganisms found in nature have not yet been studied. Little is known about the composition and function of the insect gut microbiota. Moreover, most previous studies on diversity of gut microbiota of insects relied on culture-dependent methods using traditional microbiological techniques to identify the gut microbiota (Dillon and Dillon, 2004). Traditional methods of bacterial isolation limit the species that can be grown and analyzed under laboratory conditions, although they can provide information about the biology and biochemical features of the isolated organism. Molecular approaches for characterization of 
microbes have been used in recent years. This approach based on nucleic acid sequence, particularly the 16S rRNA gene, has enabled the definition of the microbial community of insects (Brauman, 2000).

More recently, gut bacteria of the spruce beetle, Dendroctomus rufipennis, were characterized using both culture-dependent and culture-independent methods (Cardoza et al., 2006).

Knowledge of microorganisms species can facilitate studies of the function of the gut microbiota and help to define interactions among members of the gut community that can lead to the development of insect control strategies (Broderick et al., 2004).

In addition, microorganisms from microbiota help their host utilize complex molecules such as cellulose (Watanabe and Tokuda, 2001). The ability to degrade cellulose is widely distributed among various genera of Eubacteria and fungi (Mattanovich et al., 2009). The enzymes required for cellulose hydrolysis, called cellulases, are divided into three main groups: endoglucanases, cellobiohydrolases (exoglucanases) and beta-glucosidases. A current major challenge in biochemistry is to develop processes capable of breaking down lignocellulosic biomass (cellulose, hemicellulose and lignin) from sugarcane bagasse to produce second-generation ethanol. Recent studies using molecular biological tools have shown the mechanisms by which the insects and their microbes digest cellulose in the gut (Watanabe and Tokuda, 2010). Cellulolytic activities have been detected in the gut of beetle larvae, thus, the gut is considered to be a site for lignocellulose digestion (Watanabe and Tokuda, 2001). The expression of endogenous cellulases has been confirmed in the gut of mustard beetles, Phaedon cochlearine (Chrysomelidae; Sugimura et al., 2003). Thus, studies describing the microbiota of $S$. levis larvae may contribute to find novel cellulose-degrading genes within the gut of insect.

Moreover, the identification of microorganisms and their specific enzymatic activities can help in the understanding of the interactions between insects and their microorganisms and will be crucial to knowledge the biology of $S$. levis. The characterization of the microbe populations in the guts of $S$. levis larvae is a crucial first step toward detailing the interactions between these microbes and the host $S$. levis, which in turn may lead to the discovery of strategies for controlling this pest.

The study of the insect gut microbiota is needed to understand insect physiology. Therefore, this report describes the characterization of $S$. levis larva microbiota from laboratory and from field population using culture-independent molecular methods and traditional culture-dependent methods to characterize the microbiota of $S$. levis. We used traditional methods of microbial isolation and cultivation to seek microorganisms capable of degrading cellulose, a main component for the larval diet.

\section{MATERIAL AND METHODS}

\section{Sample collection and gut dissection}

S. levis larvae (15-18 days old) were collected at Fazenda Santo Antônio in Piracicaba, São Paulo, Brazil. Larvae reared under laboratory conditions were kindly provided from the Entomology Laboratory at the Sugar Cane Technology Center (CTC, Piracicaba, SP). The artificial feeding diet and maintenance conditions used are available in Degaspari et al. (1987). 
Both collections were performed in September 2007. S. levis larvae were surface sterilized by submersion in $70 \%(\mathrm{v} / \mathrm{v})$ ethanol for 3 min and rinsed in $1 \mathrm{X}$ sterilized phosphate-buffered saline (PBS; $137 \mathrm{mM} \mathrm{NaCl}, 2.7 \mathrm{mM} \mathrm{KCl}, 10 \mathrm{mM} \mathrm{Na}_{2} \mathrm{HPO}_{4}, 2 \mathrm{mM} \mathrm{KH}_{2} \mathrm{PO}_{4}, \mathrm{pH}$ 7.4) prior to dissection. Larvae were dissected in PBS using dissection scissors and the guts were withdrawn with fine-tipped forceps. The complete gut of each larva was removed for a total of 10 larvae cultivated in the laboratory and 10 collected in the field. Individual guts were placed in $1.5-\mathrm{mL}$ tubes containing $600 \mu \mathrm{L}$ TE buffer (10 mM Tris, $1 \mathrm{mM}$ EDTA, $\mathrm{pH}$ 8.0), vortexed for 5 min to permit the separation of the bacterial cells from the gut wall, and maintained at $4{ }^{\circ} \mathrm{C}$ until DNA extraction.

\section{DNA extraction}

Bacterial DNA extraction was performed directly from the larva gut with a CTAB (cetyl trimethylammonium bromide) protocol modified from Ausubel et al. (1994); which uses chemical detergents and enzymatic digestion to lyse the cells. The DNA was purified with a phenol/chloroform extraction followed by isopropanol precipitation. DNA was analyzed on a $1 \%$ agarose gel electrophoresis and quantified with a NanoDrop ${ }^{\circledR}$ ND-1000.

\section{PCR amplification}

A pool of total DNA extracted from 10 larvae each from the laboratory and the field were used to construct the $16 \mathrm{~S}$ rRNA gene libraries. The pool of the extracted DNA was PCR amplified using the following primers: 27F (5'-AGAGTTTGATCMTGGCTCAG-3') and 1492R (5'-GGTTACCTTGTTACGACTT-3') which amplify a fragment of approximately 1.5 $\mathrm{kb}$ (Weisburg et al., 1991). PCR mixtures used to amplify bacterial sequences contained about $25 \mathrm{ng}$ DNA; $0.2 \mathrm{mM}$ each dNTP; $1.25 \mathrm{U}$ Taq DNA polymerase (Invitrogen); $1.5 \mathrm{mM} \mathrm{MgCl}$ (50 mM magnesium chloride); 1X PCR buffer minus Mg (200 mM Tris, $\mathrm{pH}$ 8.4, $500 \mathrm{mM}$ $\mathrm{KCl}$ ); 10 pmol of each primer and sterile water to a final volume of $25 \mu \mathrm{L}$. PCR amplification was carried out with the following program: $94^{\circ} \mathrm{C}$ for $5 \mathrm{~min} ; 35$ cycles at $94^{\circ} \mathrm{C}$ for $1 \mathrm{~min}, 50^{\circ} \mathrm{C}$ for $1 \mathrm{~min}$ and $72^{\circ} \mathrm{C}$ for $2 \mathrm{~min}$, and a final extension at $72^{\circ} \mathrm{C}$ for $20 \mathrm{~min}$. Reactions were carried out in an MJ Research PTC 100 Thermal Cycler. Amplification products were analyzed by electrophoresis on a 1\% agarose gel and visualized under UV light after staining with ethidium bromide. PCR products were purified using the Wizard ${ }^{\circledR}$ SV Gel and PCR Clean-Up System (Promega, Madison, WI, USA) according to manufacturer recommendations.

\section{Cloning the 16S rRNA gene}

Two 16S rRNA gene genomic libraries were constructed using total DNA PCR amplified from pools of $10 \mathrm{~S}$. levis larvae from the field and 10 from the laboratory and named Levis-16S-Field and Levis-16S-Lab, respectively. Purified PCR products were cloned into a pTZ57R/T vector (Fermentas, Sinapse Biotechnologia Ltda., São Paulo, SP, Brazil) according to manufacturer instructions and transformed into competent DH10B Escherichia coli cells (Invitrogen ${ }^{\mathrm{TM}}$ Brasil Ltda., São Paulo, SP, Brazil) by electroporation (Sambrook et al., 1989). Recombinant colonies were identified using blue and white screening on LB agar medium $(10 \mathrm{~g} / \mathrm{L}$ tryptone, $5 \mathrm{~g} / \mathrm{L}$ yeast extract, $5 \mathrm{~g} / \mathrm{L}$ sodium chloride, $10 \mathrm{~g} / \mathrm{L}$ agar, $\mathrm{pH}$ 7.2) containing 
$100 \mu \mathrm{g} / \mathrm{mL}$ ampicillin, $2 \mathrm{mM}$ IPTG and $0.004 \% \mathrm{X}$-gal. The plates were incubated at $37^{\circ} \mathrm{C}$ overnight. A total of 96 white colonies were then picked onto 96 -well microplates containing $1 \mathrm{~mL}$ Circle Grow medium (BIO 101) with $100 \mu \mathrm{g} / \mathrm{mL}$ ampicillin and grown at $37^{\circ} \mathrm{C}$ for 22 h. Plasmid minipreps were done in the 96-well plate using an alkaline lysis method according to Vettore et al. (2001).

\section{Sequencing of the 16S rRNA gene $\mathrm{V} 3$ region and sequence analysis}

Two 16S rRNA gene genomic libraries were constructed, one library using S. levis larvae from the field and another with S. levis larvae from the laboratory. A total of 192 recombinant clones were sequenced and each library contained 96 clones. The sequencing of clones was performed in a MegaBACE 1000 Flexyble using the DYEnamic ET Dye Terminator Kit for MegaBACE ${ }^{\mathrm{TM}}$ (GE Healthcare do Brasil Ltda., São Paulo, SP, Brazil). The 338F (5'-ACTCCTACGGGAGGCAGCAG-3') (36) for the V3 hypervariable region from $16 \mathrm{~S}$ rRNA gene was used for sequencing. The sequences were generated using Sequence Analyzer, Base Caller Cimarron 3.12. Flanking regions with low-quality index were trimmed out. Each sequence was identified using BLASTN (http://blast.ncbi.nlm.nih.gov/Blast.cgi; Altschul et al., 1990) and Ribosomal Database Project II (RDP-II) (http://rdp.cme.msu.edu/; Chao, 1984). Sequences were assigned to operational taxonomic units (OTUs) by constructing a Kimura 2-parameter corrected distance matrix in DNADIST from the PHYLIP package (Felsenstein, 1993) and subsequently analyzing it in the distance-based OTU and richness determination software package at DOTUR (Schloss and Handelsman, 2005).

\section{Isolation of cultivable bacteria}

Bacteria were cultivated from pools of guts of the three larvae collected in field and three larvae reared in the laboratory. The pool of guts were placed in a tube with $1 \mathrm{~mL}$ PBS and vortexed for $5 \mathrm{~min}$. Six serial 10-fold dilutions were spread on plates of one-tenth strength in tryptic soy agar (TSA; Difco Laboratories: $15 \mathrm{~g} / \mathrm{L}$ pancreatic digest of casein, $5 \mathrm{~g} / \mathrm{L}$ papain digest of soybean, $5 \mathrm{~g} / \mathrm{L}$ sodium chloride, and $15 \mathrm{~g} / \mathrm{L}$ agar, $\mathrm{pH}$ 7.0) and yeast peptone dextrose agar (YPD: $20 \mathrm{~g} / \mathrm{L}$ peptone, $20 \mathrm{~g} / \mathrm{L}$ dextrose, $10 \mathrm{~g} / \mathrm{L}$ yeast extract, and $20 \mathrm{~g} / \mathrm{L}$ agar, $\mathrm{pH}$ 5.0). Plates were incubated in an incubator at $30^{\circ} \mathrm{C}$ for 10 days under aerobic conditions. The number of bacterial colonies on all plates was counted daily for all dilutions. Each single colony was isolated in pure culture and categorized based on Gram stain test and microscopic observations. Yeasts and bacterial colonies were also classified based on morphological parameters (shape, color and colony size). Isolated fungi were visualized by laser confocal microscopy (Zeiss LM510) in order to identify differences among them (data not shown).

\section{Assay of cellulolytic activity}

The isolated colonies (fungi and bacteria) were tested for the ability to degrade carboxymethylcellulose $(\mathrm{CMC})$ on $\mathrm{CMC}$ agar medium $(15 \mathrm{~g} / \mathrm{L}$ agar, $5 \mathrm{~g} / \mathrm{L} \mathrm{CMC}$ and $0.2 \mathrm{~g} / \mathrm{L}$ yeast extract). Plates were incubated for 4 days at $28^{\circ} \mathrm{C}$ and treated with Congo red to confirm the presence or absence of endoglucanase activity (Teather and Wood, 1982). The CMC agar medium was flooded with an aqueous solution of $0.2 \%$ Congo red (w/v) for $30 \mathrm{~min}$. Congo 
red solution was then poured off and plates were treated by flooding with $1 \mathrm{M} \mathrm{NaCl}$ for $15 \mathrm{~min}$. The degradation of CMC was indicated by a clear halo around the colony. The enzyme activity was calculated by diameter of clear zone divided by the diameter of the colony (Hankin and Anagnostakis, 1975). Pichia pastoris KM71H was used as a positive control for cellulolytic activity and $E$. coli DH5 $\alpha$ was used as a negative control (Mattanovich et al., 2009).

\section{RESULTS}

\section{S rRNA gene sequence analysis}

Of the 96 clones sequenced in each library, 92 laboratory clones and 84 field clones provided useful sequence information. DOTUR analysis showed that the composite sequence collection contained 80,48, 37, and 19 OTUs from larvae collected in the field and $84,44,33$, and 19 OTUs from larvae reared in laboratory, when an OTU was defined as a group of unique sequences or sequences with 97,95 or $90 \%$ similarity. Using the Chao 1 nonparametric richness estimator (Chao, 1984), we predicted that the clone library from the field population would yield 52 versus 46 OTUs from the library of the laboratory population when defining an OTU as a group of sequences with $<5 \%$ difference from each other.

Both clone libraries contained representatives from the Gamma-Proteobacteria, Beta-Proteobacteria, Alpha-Proteobacteria, Firmicutes, and Bacteroidetes phyla (Table 1). The 16S rRNA gene sequences clustered with 14 genera, plus one Candidatus group, one uncultured group assigned to the Flavobacteriaceae, and one uncultured group assigned to the Enterobacteriaceae family. Phylotypes found in the laboratory belonged to eight genera plus one uncultured Candidatus group, while eight genera and one group from Candidatus were observed in the field population. Burkholderia, Caulobacter, Citrobacter, Diaphorobacter, Methylophilus, and Streptococcus were found only in the laboratory clone library; Buchnera, Raoultella, Enterobacter, Lactococcus, Leuconostoc, and Sphingobacterium were found only in the field clone library. Klebsiella and Acinetobacter were common in both libraries.

To estimate the relative abundances of different phylotypes of bacterial populations found within the clone libraries from field and laboratory, we restricted our considerations to the genus level (similarity index of sequences $\geq 95 \%$ ), including the Candidatus category. The category Candidatus Nardonella is predominantly found in the clone library from the laboratory population ( $84 \%$ ) but present in only $24 \%$ of clone library from the field population. Enterobacter (31\%), Raoultella (20\%) and Klebsiella (17\%) were the most abundant genera found in clone library from the field population (Table 1). The Enterobacteriaceae family was found within the clone library from field (69\%) but present in only a small proportion $(5.5 \%)$ of the clone library from laboratory (Table 1). Clones belonging to the taxonomic class Beta-Proteobacteria were found only in the laboratory library (Table 1). The second most frequently identified type of $16 \mathrm{~S}$ rRNA gene sequence in the laboratory library matched that of some uncultured Flavobacteriaceae (4\%).

The Shannon index (DOTUR) showed that the field population $\left(\mathrm{H}^{\prime}=3.36\right)$ has a slightly higher diversity than the laboratory population $\left(\mathrm{H}^{\prime}=3.26\right)$ (similarity index of sequences $\geq 95 \%$ ). Rarefaction curves for both populations are shown in Figure 1 . 
Table 1. Composition of gut bacterial communities of Sphenophorus levis from field and from laboratory.

\begin{tabular}{|c|c|c|c|}
\hline \multicolumn{2}{|c|}{ Phylogenetic affiliation of $16 \mathrm{~S}$ rRNA gene sequences } & \multicolumn{2}{|c|}{ Number of sequences found in each phylogenetic group } \\
\hline & & Laboratory $(\mathrm{N}=92)$ & Field $(\mathrm{N}=84)$ \\
\hline \multicolumn{4}{|l|}{ Gamma-Proteobacteria } \\
\hline & Candidatus Nardonella & 77 & 20 \\
\hline \multirow[t]{6}{*}{ Enterobacteriaceae } & Buchnera sp & 0 & 1 \\
\hline & Klebsiella sp & 1 & 14 \\
\hline & Citrobacter $\mathrm{sp}$ & 1 & 0 \\
\hline & Raoultella $\mathrm{sp}$ & 0 & 17 \\
\hline & Enterobacter $\mathrm{sp}$ & 0 & 26 \\
\hline & Uncultured Enterobacteriaceae & 1 & 0 \\
\hline Moraxellaceae & Acinetobacter $\mathrm{sp}$ & 2 & 1 \\
\hline \multicolumn{4}{|l|}{ Beta-Proteobacteria } \\
\hline Burkholderiaceae & Burkholderia sp & 1 & 0 \\
\hline Comamonadaceae & Diaphorobacter sp & 2 & 0 \\
\hline Methylophilaceae & Methylophilus sp & 1 & 0 \\
\hline \multicolumn{4}{|l|}{ Alpha-Proteobacteria } \\
\hline Caulobacteraceae & Caulobacter $\mathrm{sp}$ & 1 & 0 \\
\hline \multicolumn{4}{|l|}{ Firmicutes } \\
\hline \multirow[t]{2}{*}{ Streptococcaceae } & Streptococcus sp & 1 & 0 \\
\hline & Lactococcus sp & 0 & 3 \\
\hline Leuconostocaceae & Leuconostoc $\mathrm{sp}$ & 0 & 1 \\
\hline \multicolumn{4}{|l|}{ Bacteroidetes } \\
\hline Flavobacteriaceae & Uncultured Flavobacteriaceae & 4 & 0 \\
\hline Sphingobacteriaceae & Sphingobacterium sp & 0 & 1 \\
\hline
\end{tabular}

Rarefaction Curve $\cdot$ Laboratory

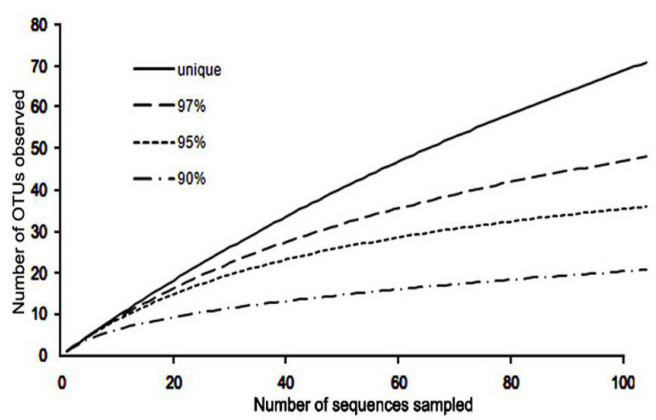

Rarefaction Curve - Field

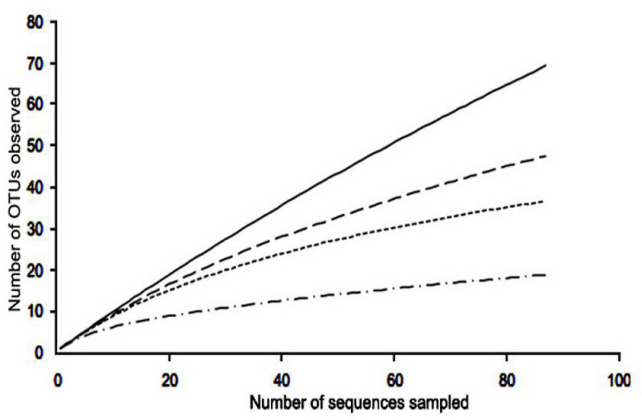

Figure 1. Rarefaction analyses from 16S rRNA gene libraries constructed from Sphenophorus levis larvae isolated in the field and in the laboratory. Rarefaction curves were constructed based on DOTUR analyses. Rarefaction curves are shown for unique sequences and sequences with 97,95 and $90 \%$ similarity. OTUs = operational taxonomic units.

\section{Culture-dependent analysis}

The only microorganisms that grew on YPD medium, $\mathrm{pH}$ 5.0, were isolated from pool of larva insect gut isolated from the field; those that grew on TSA medium, $\mathrm{pH} 7.0$, were isolated from field and laboratory larvae. A BLAST search through BLASTN and the RDP-II data bank associated the isolated strains with the Alpha-Proteobacteria, Gamma-Proteobacteria, Firmicutes, and Acidobacteria phyla, totaling 12 genera and 1 uncultured group (Table 2). Seven genera were found in larvae reared in the laboratory [Bacillus $(46.66 \%)$, Micrococcus (6.66\%), Microbacterium (6.66\%), Asaia (6.66\%), Acinetobacter (6.66\%), Leuconostoc 
(13.3\%), and Paenibacillus (13.3\%)] and eight genera were found in field isolates [Bacillus (11.53\%), Lactococcus (19.2\%), Klebsiella (11.53\%), Weissella (30.76\%), Microbacterium (3.85\%), Asaia (11.53\%), Pantoea (3.85\%), and Curtobacterium (3.85\%)]. Micrococcus, Acinetobacter, Leuconostoc, and Paenibacillus genera were found exclusively in the laboratory population while Lactococcus, Klebsiella, Weissella, Pantoea, and Curtobacterium were found exclusively in the field population. Bacillus, Microbacterium and Asaia genera were found in both populations. The Shannon index based on 16S DNA sequences from culturedependent isolates showed that the field population $\left(\mathrm{H}^{\prime}=2.97\right)$ has a slightly higher diversity than the laboratory population $\left(H^{\prime}=2.57\right.$ ) (similarity index of sequences $\geq 97 \%$ ).

\begin{tabular}{|c|c|c|}
\hline Genera (similarity $\geq 95 \%$ ) & Laboratory $(\mathrm{N}=15)$ & Field $(\mathrm{N}=26)$ \\
\hline \multicolumn{3}{|l|}{ Gamma-Proteobacteria } \\
\hline Klebsiella sp & 0 & 3 \\
\hline Pantoea sp & 0 & 1 \\
\hline Acinetobacter $\mathrm{sp}$ & 1 & 0 \\
\hline \multicolumn{3}{|l|}{ Alpha-Proteobacteria } \\
\hline Asaia sp & 1 & 3 \\
\hline \multicolumn{3}{|l|}{ Firmicutes } \\
\hline Bacillus sp & 7 & 3 \\
\hline Lactococcus sp & 0 & 5 \\
\hline Weissella $\mathrm{sp}$ & 0 & 8 \\
\hline Leuconostoc sp & 2 & 0 \\
\hline Paenibacillus sp & 2 & 0 \\
\hline \multicolumn{3}{|l|}{ Acidobacteria } \\
\hline Micrococcus sp & 1 & 0 \\
\hline Microbacterium sp & 1 & 1 \\
\hline Curtobacterium sp & 0 & 1 \\
\hline Uncultured bacterium partial $16 \mathrm{~S}$ rRNA gene & 0 & 1 \\
\hline
\end{tabular}

The sequence information based on the V3 hypervariable region from 16S rRNA gene analysis allowed us to group the cultivable bacteria isolated from the laboratory $(\mathrm{N}=15)$ and the field $(\mathrm{N}=26)$ in OTUs. DOTUR analysis showed that when an OTU was defined as a group of sequences with no differences (unique sequences) or 97,95 or $90 \%$ similar sequences, 28, 22, 17, and 14 OTUs were found in the composite clone sequences from the gut bacteria of S. levis field populations and 19, 14, 13, and 8 OTUs were found in the laboratory population.

\section{Cultivable microorganisms and the cellulolytic assay}

Four filamentous fungi (SLFF1, SLFF2, SLFF3, and SLFF4) were isolated from the guts of $S$. levis larvae from the field and the laboratory. All bacterial and fungal isolates were tested on CMC medium. Bacteria from the Paenibacillus, Bacillus, Enterobacter, Klebsiella, and Pantoea genera presented cellulolytic activity on CMC medium (Figure 2). Three of these bacteria (Enterobacter, Klebsiella and Pantoea) were isolated from the field and three (Paenibacillus, Bacillus and Micrococus) were isolated from the laboratory. The CMCase activity assay was also carried out for all filamentous fungi, but only SLFF1 (isolated from the field) and SLFF2 (isolated from the laboratory) presented cellulolytic activity. 


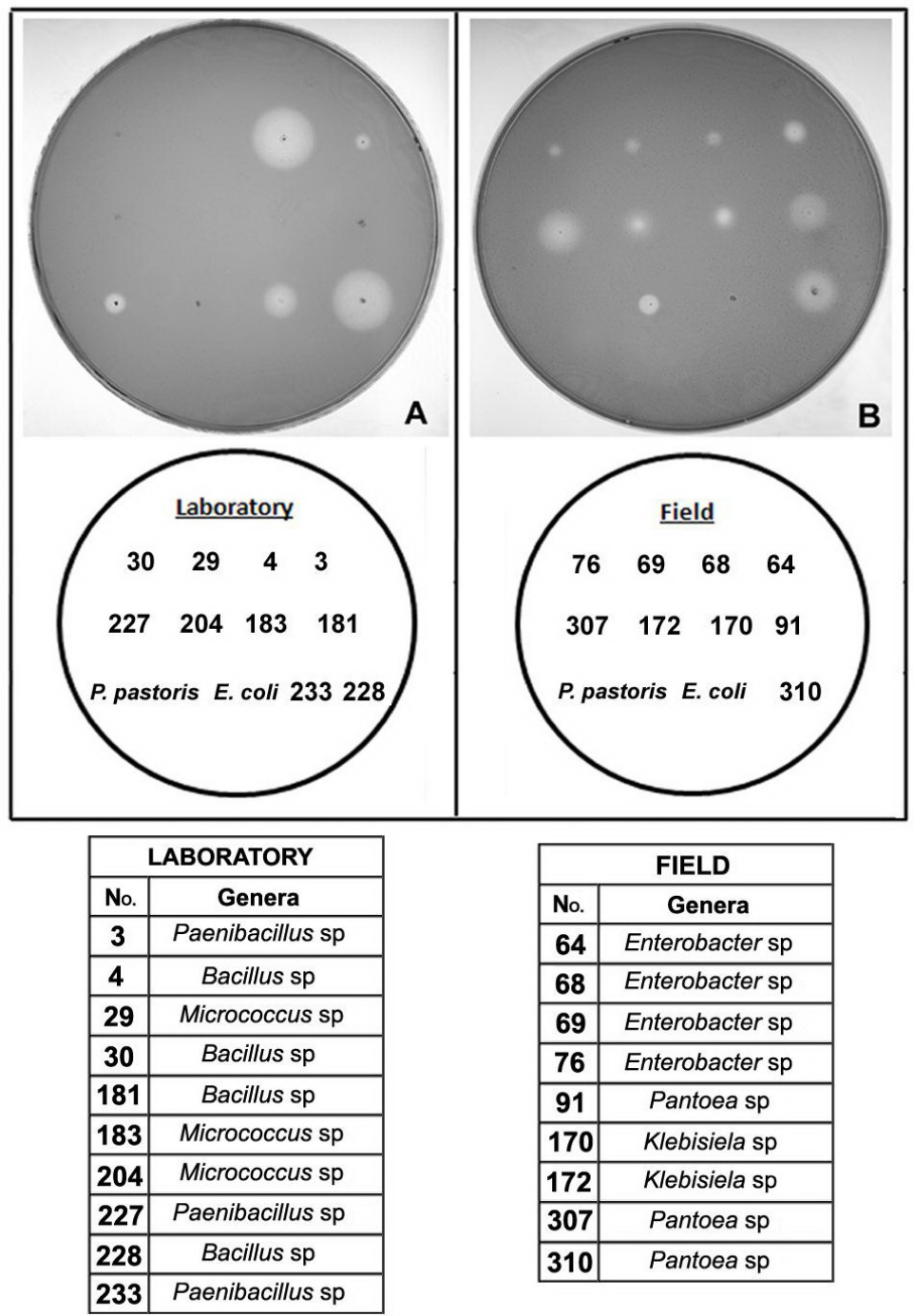

Figure 2. Cellulolytic activity assay. Clear halos around the colonies represent cellulolytic activity on CMC agar stained with Congo Red. A. Bacteria isolated from the intestinal microbiota of laboratory larvae. B. Bacteria isolated from the intestinal microbiota of field larvae. Pichia pastoris KM71H: positive control; Escherichia coli DH5 $\alpha$ : negative control.

Among all cultivable bacteria that had the 16S rRNA gene sequenced, 24.4\% (about $2 / 3$ isolated from laboratory and $1 / 3$ from field) presented cellulolytic activity. The cellulolytic activity of each strain was compared to that of the positive and negative controls (Figure 3). The strains with the highest cellulolytic activity were No. 4 (Bacillus sp) and No. 228 (Bacillus $\mathrm{sp}$ ) from the laboratory population and No. 170 (Klebsiella $\mathrm{sp}$ ) from the field population based on the Student $t$-test $(\mathrm{P}<0.05)$ (Figures 2 and 3 ). 
Field

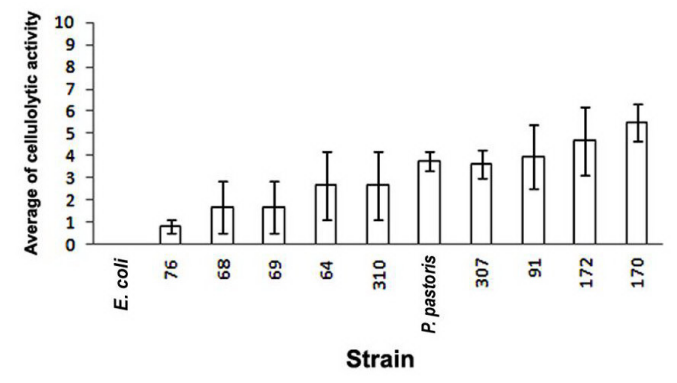

Laboratory

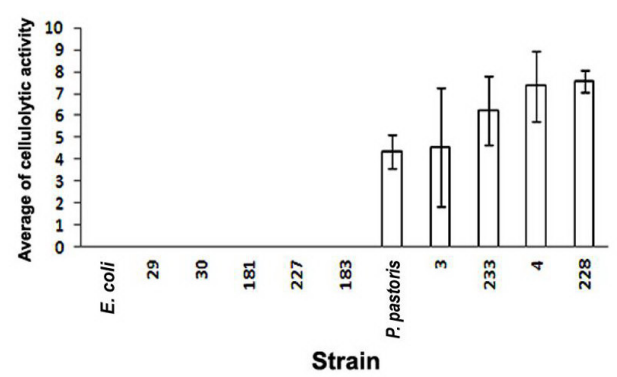

Figure 3. Comparison between the cellulolytic activity of strains isolated from the laboratory and field population and positive (Pichia pastoris $\mathrm{KM} 71 \mathrm{H})$ and negative (Escherichia coli DH5 $\alpha$ ) controls. The graph represents cellulolytic activity on the y-axis (diameter of the clear zone divided by the diameter of the colony) of each strain expressed on the $\mathrm{x}$-axis. Significance was calculated using the Student $t$-test $(\mathrm{P}<0.05)$. The strain numbers are the same as those shown in Figure 2.

The sequences were deposited in GenBank (http://www.ncbi.nlm.nih.gov/Genbank/ index.html) under the accession Nos. FJ593042 to FJ593133 and FJ626247 to FJ626351.

\section{DISCUSSION}

In the present study, we isolated microorganisms from pools of the guts of field-collected and laboratory-reared larvae on TSA medium, $\mathrm{pH}$ 7.0. The intestinal microbiota of laboratory larvae could be also pre-selected due to artificial culture conditions, which may alter the composition of intestinal microbiota. On the other hand, different feeding stages (constant feeding insects versus insects that are starved or have fed on another type of diet for several days) may also modify the composition of the microbiota (Dillon and Dillon, 2004). Furthermore, the compounds contained in each medium can be selective for some types of microorganisms.

Phylotypes found in the laboratory community through culture-independent methods belong to eight genera, one group from the Candidatus category and two uncultured groups (Enterobacter and Flavobacteriaceae), while eight genera and one group from the Candidatus category were observed in the field population. Gamma-Proteobacteria (Candidatus Nardonella) was the predominant group found in larvae microbiota from the laboratory population, but it was only found in small quantities in the field population. Candidatus Nardonella (GammaProteobacteria) is an endosymbiont frequently found in weevils (Coleoptera: Curculionidae) such as Cosmopolites sordidus, Metamasius callizona, M. hemipterus, Rhynchophorus palmarum, Scyphophorus yuccae, Sphenophorus abbreviate, Yuccaborus frontalis (Lefèvre et al., 2004). All sequences related to Candidatus Nardonella matched the "partial 16 S ribosomal RNA gene sequence of the endosymbiont of $M$. hemipterus" reported by Lefèvre et al. (2004). M. hemipterus (L.) (Nardon et al., 1984) is the main species associated with banana and plantain (Musa spp).

Comparing the results of culture-independent and culture-dependent methods, we observed that representatives of the Firmicutes, Alpha-Proteobacteria, Gamma-Proteobacteria phyla were present in both populations. Acidobacteria was only found via culture-dependent 
methods and Beta-Proteobacteria and Bacteroidetes were only detected by culture-independent methods.

The insect gut microbiota is considered to be a complex ecosystem containing over a hundred bacterial species including anaerobes and facultative anaerobes (Brauman, 2000). Organisms from the Enterobacteriaceae family that have the ability to ferment sugar (Ewing, 1986) seem to play a key role in the S. levis field population as they represent $70 \%$ of the total sequences found in the 16S rRNA gene library. Weevils and other insects harbor various maternally transmitted Enterobacteriaceae (Lefèvre et al., 2004); members of the Enterobacteriaceae are found in many environments, including the guts of other termite and insect species (Dillon and Dillon, 2004; Delalibera et al., 2005; Dunn and Stabb, 2005). The desert locust, Schistocerca gregaria, also possesses an abundant gut microbiota consisting predominantly of Enterobacteriaceae (Hunt and Charnley, 1981). The rice weevil Sitophilus oryzae (Coleoptera: Rhynchophoridae) shares an endosymbiotic association with a so-called $S$. oryzae principal endosymbiont (SOPE), a Gram-negative bacterium belonging to the Enterobacteriaceae family (Heddi et al., 1998). A simplified gut bacteria community may reflect the type of food available to laboratory-reared insects, or other environmental factors that differ between field and laboratory populations (Mead et al., 1988). In the field, insect larvae can only feed on sugarcane, while in the laboratory, insect larvae receive sugarcane bagasse mixed with other compounds like proteins, mineral salts and vitamins present in the artificial diet. This artificial diet also contains antimicrobial agents such as Nipagin (Methylparaben; $35 \mathrm{mg} / \mathrm{mL}$ ) and Wintomylon (Nalidixic acid; $0.0625 \mathrm{mg} / \mathrm{mL}$ ) that can interfere with microbial diversity. Previous studies have shown that the composition of the gut microbiota of Automeris zucana third-instar larvae (Lepidoptera-Saturniidae) exposed to different feeding habits could be altered, although this did not change the predominance of microbes passed by maternal vertical transmission in the egg chorion that the newly hatched larvae eat (Sittenfeld et al., 2002). Diet also has a significant impact on the composition of the gut microbiota of the cockroach (Kane and Breznak, 1991) and house cricket (Santo Domingo et al., 1998a,b).

The rarefaction curves obtained here indicate that the $\mathrm{OTU}_{0.03}$ from laboratory and field larval gut population has been sampled adequately. Although the bacterial diversity of field population and laboratory population were very similar, the Shannon index showed that the microbial community of laboratory-reared insects was dominated by a single phylotype Candidatus Nardonella. The $S$. levis microbiota is relatively diverse compared to what has been described for other insects, and it is compatible with what is found in other studies of the intestinal microbiota of coleopterans (Geib et al., 2009).

The presence of cellulolytic microorganisms that are capable of degrading sugarcane cellulose and hemicellulose seems to be necessary in the intestinal tract of S. levis. A CMC assay showed that three genera of bacteria from field isolates and three from laboratory isolates presented the ability to degrade CMC. Microorganisms from the Paenibacillus genus were isolated from laboratory larvae; this was the most abundant group of organisms to present CMCase activity. The strain Paenibacillus sp BP-23 (formerly Bacillus sp BP-23) (Blanco and Pastor, 1993) has been reported to have a multi-enzymatic glucanase system, including several cellulases (Pastor et al., 2001) and xylanases (Blanco et al., 1999). Several cellulolytic microorganisms were found in both populations, although the highest cellulolytic activity was observed in bacteria isolated from the laboratory population. While more cellulolytic microorganisms appear in the field insects, the highest levels of activity appear in microorganisms 
from the laboratory population. This may suggest that there has been a reduction in the diversity but a selection of more cellulolytic active bacteria.

The absence of cellulolytic activity among some types of microorganisms isolated from S. levis may be dietary dependent. According to Delalibera et al. (2005), cultures of cellulolytic microorganisms from $S$. vestita intestinal microbiota that presented CMC-degrading activity weakly digested filter paper strips. This indicates that a set of microbes producing a mixture of enzymes is probably necessary for complete digestion of cellulose and that this cannot be accomplished by single isolates. Filamentous fungi that presented cellulolytic activity need to be better characterized biochemically.

Although this is an initial study to characterize the microbiota from $S$. levis and the first step to a better understanding of the functions and interactions that can occur in the gut of S. levis, additional intensive efforts are needed to genetically and biochemically characterize the microbiota identified.

\section{ACKNOWLEDGMENTS}

We are grateful to the Centro de Tecnologia Canavieira for kindly providing us with Sphenophorus levis larvae. We also thank Professor Clovis Wesley Oliveira de Souza for helping us with bacterial identification. Research supported by FAPESP (CBME, CEPID Proc. \#98/14138-2). R. Rinke was the recipient of a scholarship from CAPES (Coordenação de Aperfeiçoamento de Pessoal de Nível Superior). F.P.P. Fonseca was the recipient of a FAPESP scholarship.

\section{REFERENCES}

Altschul SF, Gish W, Miller W, Myers EW, et al. (1990). Basic local alignment search tool. J. Mol. Biol. 215: 403-410.

Ausubel F, Brent R, Kingston R and Seidman J (1994). Current Protocols in Molecular Biology. John Wiley and Sons Inc., New York, 27 (1): 2.4.1-2.4.2.

Blanco A and Pastor FIJ (1993). Characterization of cellulase-free xylanases from the newly isolated Bacillus sp strain Bp-23. Can. J. Microbiol. 39: 1162-1166.

Blanco A, Diaz P, Zueco J, Parascandola P, et al. (1999). A multidomain xylanase from a Bacillus sp. with a region homologous to thermostabilizing domains of thermophilic enzymes. Microbiology 145: 2163-2170.

Brauman A (2000). Effect of gut transit and mound deposit on soil organic matter transformations in the soil feeding termite: a review. Eur. J. Soil Biol. 36: 117-125.

Broderick NA, Raffa KF, Goodman RM and Handelsman J (2004). Census of the bacterial community of the gypsy moth larval midgut by using culturing and culture-independent methods. Appl. Environ. Microbiol. 70: 293-300.

Cardoza YJ, Klepzig KD and Raffa KF (2006). Bacteria in oral secretions of an endophytic insect inhibit antagonistic fungi. Ecol. Entomol. 31: 636-645.

Chao A (1984). Non-parametric estimation of the number of classes in a population. Scand. J. Stat. 11: 265-270.

Degaspari N, Botelho PSM, Almeida LC and Castilho HJ (1987). Biology of Sphenophorus levis Vaurie, 1978 (Col, Curculionidae), with artificial diet and in the field. Pesq. Agropec. Bras. 22: 553-558.

Delalibera IJ, Handelsman J and Raffa KF (2005). Contrasts in cellulolytic activities of gut microorganisms between the wood borer, Saperda vestita (Coleoptera: Cerambycidae), and the bark beetles, Ips pini and Dendroctonus frontalis (Coleoptera: Curculionidae). Environ. Entomol. 34: 541-547.

Dillon RJ and Dillon VM (2004). The gut bacteria of insects: nonpathogenic interactions. Annu. Rev. Entomol. 49: 71-92.

Dunn AK and Stabb EV (2005). Culture-independent characterization of the microbiota of the ant lion Myrmeleon mobilis (Neuroptera: Myrmeleontidae). Appl. Environ. Microbiol. 71: 8784-8794.

Ewing WH (1986). Edwards and Ewing's Identification of Enterobacteriaceae, 4th edn. Elsevier, New York.

Felsenstein J (1993). PHYLIP (Phylogeny Inference Package) Version 3.5c. Department of Genetics, University of Washington, Seattle. 
Geib SM, Jimenez-Gasco MDM, Carlson JE, Tien M, et al. (2009). Effect of host tree species on cellulase activity and bacterial community composition in the gut of larval Asian Longhorned Beetle. Insect Symbiont Interact. 38: 686699.

Hankin L and Anagnostakis SL (1975). The use of solid media for detection of enzyme production by fungi. Mycology 67: 597-607.

Heddi A, Charles H, Khatchadourian C, Bonnot G, et al. (1998). Molecular characterization of the principal symbiotic bacteria of the weevil Sitophilus oryzae: a peculiar G + C content of an endocytobiotic DNA J. Mol. Evol. 47: 52-61.

Hunt J and Charnley AK (1981). Abundance and distribution of the gut flora of the desert locust, Schistocerca gregaria. J. Invertebr. Pathol. 38: 378-385.

Kane MD and Breznak JA (1991). Effect of host diet on production of organic acids and methane by cockroach gut bacteria. Appl. Environ. Microbiol. 57: 2628-2634.

Lefèvre C, Charles H, Vallier A, Delobel B, et al. (2004). Endosymbiont phylogenesis in the dryophthoridae weevils: evidence for bacterial replacement. Mol. Biol Evol. 21: 965-973.

Mattanovich D, Callewaert N, Rouze P, Lin YC, et al. (2009). Open access to sequence: browsing the Pichia pastoris genome. Microb. Cell Fact. 8: 53.

Mead LJ, Khachatourians GG and Jones GA (1988). Microbial ecology of the gut in laboratory stocks of the migratory grasshopper, Melanoplus sanguinipes (Fab.) (Orthoptera: Acrididae). Appl. Environ. Microbiol. 54: 1174-1181.

Nardon P, Kermarrec A and Nardon C (1984). Distinctive morphological features of the larvae of Cosmopolites sordidus (Germar) and Metamasius hemipterus (Linne) (Coleoptera-Curculionidae), banana-tree parasites. Fruits 39: 180187.

Pastor FI, Pujol X, Blanco A, Vidal T, et al. (2001). Molecular cloning and characterization of a multidomain endoglucanase from Paenibacillus sp BP-23: evaluation of its performance in pulp refining. Appl. Microbiol. Biotechnol. 55: 61-68.

Pittman GW, Brumbley SM, Allsopp PG and O'Neill SL (2008). Assessment of gut bacteria for a paratransgenic approach to control Dermolepida albohirtum larvae. Appl. Environ. Microbiol. 74: 4036-4043.

Sambrook J, Fritsch EF and Maniatis T (1989). Molecular Cloning: A Laboratory Manual, 2nd edn. Cold Spring Harbor Laboratory Press, Cold Spring Harbor.

Santo Domingo JW, Kaufman JW, Klug MJ and Holben WE (1998a). Influence of diet on the structure and function of the bacterial hindgut community in crickets. Mol. Ecol. 7: 761-767.

Santo Domingo JW, Kaufman MG, Klug MJ and Tiedje JM (1998b). Characterization of the cricket hindgut microbiota with fluorescently labeled rRNA-targeted oligonucleotide probes. Appl. Environ. Microbiol. 64: 752-755.

Schloss PD and Handelsman J (2005). Introducing DOTUR, a computer program for defining operational taxonomic units and estimating species richness. Appl. Environ. Microbiol. 71: 1501-1506.

Sittenfeld A, Uribe-Lorio L, Mora M, Nielsen V, et al. (2002). Does a polyphagous caterpillar have the same gut microbiota when feeding on different species of food plants? Rev. Biol. Trop. 50: 547-560.

Sparovek G, Berndes G and Egeskog A (2007). Sugarcane ethanol production in Brazil: a Biofuels. Bioref 1: 270-282.

Sugimura M, Watanabe H, Lo N and Saito H (2003). Purification, characterization, cDNA cloning and nucleotide sequencing of a cellulase from the yellow-spotted longicorn beetle, Psacothea hilaris. Eur. J. Biochem. 270: $3455-$ 3460.

Teather RM and Wood PJ (1982). Use of Congo red-polysaccharide interactions in enumeration and characterization of cellulolytic bacteria from the bovine rumen. Appl. Environ. Microbiol. 43: 777-780.

Vanin SA (1990). A new species of Sphenophorus schoenher from Brazil (Coleoptera,Curculionidade, Rhynchophorinae). Rev. Bras. Entomol. 34: 697-701.

Vettore AL, da Silva FR, Kemper EL and Arruda P (2001). The libraries that made SUCEST. Genet. Mol. Biol. 24: 1-7.

Watanabe H and Tokuda G (2001). Animal cellulases. Cell Mol. Life Sci. 58: 1167-1178.

Watanabe H and Tokuda G (2010). Cellulolytic systems in insects. Annu. Rev. Entomol. 55: 609-632.

Weisburg WG, Barns SM, Pelletier DA and Lane DJ (1991). 16S ribosomal DNA amplification for phylogenetic study. J. Bacteriol. 173: 697-703. 